\title{
Assessment of dysfunction in aortic regurgitation by stress-shortening relationship
}

\author{
Robert J. Weiss, Andrew J. Buda, Mary S. LeMire and Bertram Pitt \\ Division of Cardiology, Department of Internal Medicine, University of Michigan Hospitals, Ann Arbor, \\ Michigan \\ (Received 9 April 1984; revision accepted 11 February 1985)
}

\begin{abstract}
Weiss RJ, Buda AJ, LeMire MS, Pitt B. Assessment of dysfunction in aortic regurgitation by stress-shortening relationship. Int J Cardiol 1985;8:475-486.
\end{abstract}

Some patients with aortic regurgitation develop irreversible left ventricular dysfunction. The purpose of this study was to noninvasively examine left ventricular function in patients with aortic regurgitation by determining the end-systolic stressshortening relationship using M-mode echocardiography. Ten normal volunteers and 10 patients with chronic, isolated aortic regurgitation were studied at rest and following load and inotropic alteration by cold pressor testing. The baseline ejection phase indices of ejection fraction and percent fractional shortening did not distinguish between normals and patients with aortic regurgitation $(74.6 \% \pm 2.8 \%$ versus $67.0 \% \pm$ $4.2 \%, P=$ NS and $37.6 \% \pm 2.4 \%$ versus $31.6 \% \pm 2.7 \%, P=$ NS, respectively.) Endsystolic stress was significantly greater in patients with aortic regurgitation both at rest $\left(107.8 \pm 11.6\right.$ dynes $/ \mathrm{cm}^{2} \times 10^{-3}$ versus $68.4 \pm 4.8$ dynes $/ \mathrm{cm}^{2} \times 10^{-3}, P<$ $0.005)$ and after cold pressor intervention $\left(122.8 \pm 13.0\right.$ dynes $/ \mathrm{cm}^{2} \times 10^{-3}$ versus $80.1 \pm 4.0$ dynes $\left./ \mathrm{cm}^{2} \times 10^{-3}, P<0.005\right)$. Normals showed increased fractional shortening in the presence of increasing end-systolic stress. Patients with aortic regurgitation showed decreased fractional shortening during increased stress. This response suggests either left ventricular dysfunction with increasing stress or decreased myocardial contractile reserve after cold pressor inotropic stimulation. Endsystolic stress-percent fractional shortening relationship may be a sensitive indicator of early left ventricular dysfunction in patients with aortic regurgitation.

(Key words: aortic regurgitation; echocardiography; myocardial function)

Correspondence to: Andrew J. Buda, M.D., Division of Cardiology, University of Michigan Hospitals, Ann Arbor, MI 48109, U.S.A. 


\section{Introduction}

There has been considerable controversy concerning the assessment of the degree of left ventricular dysfunction in patients with chronic aortic regurgitation. Physical examination [1-3], cardiomegaly on chest X-ray [4], left ventricular dimensions as measured by echocardiography $[5,6]$, and abnormal ejection phase indices such as ejection fraction and percent fractional shortening as measured by catheterization [7-9] radionuclide ventriculography $[10,11]$ or echocardiography $[5,6,12]$ have all been used to describe both clinically apparent and inapparent left ventricular dysfunction. Recently, Suga, Sagawa, and co-workers have suggested that the preload-insensitive relationship of end-systolic stress and end-systolic volume-dimension relation may better define myocardial contractility $[13,14]$ particularly in volume overload states [15]. The purpose of this study was to attempt to define left ventricular function noninvasively by $\mathrm{M}$-mode echocardiography in patients with chronic aortic regurgitation as compared to a group of normal volunteers. Ejection phase indices and the end-systolic stress-percent fractional shortening relationship were determined. Cold pressor testing which has been shown to both increase afterload and have a direct inotropic effect $[16,17]$ was used to noninvasively alter this relationship.

\section{Materials and Methods}

\section{Patient Population}

Ten normal volunteers were compared to 10 consecutive patients with chronic aortic regurgitation. Eight of the patients were asymptomatic with 2 (patients 4 and 8) having New York Heart Association Class III congestive heart failure. All patients had idiopathic aortic regurgitation except for patient 8 who had Marfan's syndrome with chronic aortic dissection and patient 3 who had a history of rheumatic fever. Four patients underwent cardiac catheterization (patients 1, 2, 5, 10). None of the patients had other associated valvular lesions or coronary artery disease. Patients 5 and 6 had rest and exercise radionuclide ventriculograms with a normal increase in ejection fraction, while patients 2 and 8 had a fall in ejection with exercise [11]. Only patients 4 and 8 had echocardiographic end-systolic diameters $>55 \mathrm{~mm}$, a suggested sign of myocardial dysfunction [5]. Thus, based on symptoms, angiocardiography, radionuclide ejection fraction response to exercise, and echocardiographic end-systolic diameter, only 4 of the 10 patients were predicted to have decreased myocardial function.

\section{Echocardiographic Examination}

All subjects underwent $\mathrm{M}$-mode echocardiographic examination with a $2.25 \mathrm{MHz}$ transducer in the left lateral position. Blood pressures were obtained by sphygmomanometer with the stethoscope diaphragm over the brachial artery. All blood pressures obtained in each study were done by the same investigator. Posterior 
wall thickness $\left(\mathrm{PWT}_{\mathrm{s}}\right.$ ) was measured by the leading edge to leading edge method. Left ventricular internal dimension in diastole $\left(\right.$ LVID $\left._{d}\right)$ was measured from the interventricular septal endocardium to the posterior wall endocardium at the peak of the electrocardiogram $R$ wave. Left ventricular internal diameter in systole (LVID ) was measured from the septal endocardium to the posterior wall endocardium at the smallest ventricular dimension. The percent fractional shortening ( $\% \Delta \mathrm{D})$ was calculated from the equation: $\mathrm{LVID}_{\mathrm{d}}-\mathrm{LVID}_{\mathrm{s}} / \mathrm{LVID}_{\mathrm{d}} \times 100 \%=\% \Delta \mathrm{D}$. The ejection fraction $(E F)$ was calculated using the cube method [18]: $\left(\operatorname{LVID}_{d}\right)^{3}-\left(\operatorname{LVID}_{\mathrm{s}}\right)^{3} /\left(\mathrm{LVID}_{\mathrm{d}}\right)^{3}$ $\times 100 \%=\mathrm{EF}$. Systolic blood pressure (SBP) measured in $\mathrm{mm} \mathrm{Hg}$ was converted to dynes $/ \mathrm{cm}^{2}$ by multiplying by a factor of 1332 dynes $/ \mathrm{cm}^{2} \mathrm{~mm} \mathrm{Hg}$. The end-systolic meridional stress (ESS) was calculated by the equation: $\mathrm{ESS}=0.334 \times \mathrm{SBP} \times$ $\mathrm{LVID}_{\mathrm{s}} / \mathrm{PWT}_{\mathrm{s}} \times\left(1+\mathrm{PWT}_{\mathrm{s}} / \mathrm{LVID}_{\mathrm{s}}\right)[19,20]$.

\section{Cold Pressor}

Cold pressor testing was performed by placing the subject's hand in ice water for $1 \mathrm{~min}$ with blood pressures obtained at baseline ${ }_{2} 30 \mathrm{sec}$, and $60 \mathrm{sec}$. Continuous M-mode echocardiograms were obtained. Blood pressure, end-systolic stress, ejection fraction, and percent fractional shortening at baseline and after one minute of immersion in the cold water were compared.

\section{Statistical Analysis}

Student's $t$-test was used to analyze the data. A statistically significant difference was defined as $P<0.05$.

\section{Results}

\section{Normals}

Normal subjects (Table 1) had an ejection fraction of $74.6 \% \pm 2.8 \%$ (mean \pm standard error of mean) at rest which changed to $80.9 \% \pm 1.4 \%$ after $1 \mathrm{~min}$ of cold pressor testing $(P<0.05)$. Resting percent fractional shortening was $37.6 \% \pm 2.4 \%$ compared to $43.0 \% \pm 1.5 \%$ after cold pressor $(P<0.025)$. End-systolic stress was $68.4 \pm 4.8$ dynes $/ \mathrm{cm}^{2} \times 10^{-3}$ at baseline and $80.1 \pm 4.0$ dynes $/ \mathrm{cm}^{2} \times 10^{-3}$ after intervention $(P<0.05)$. The average increase in blood pressure was $12.6 \pm 1.3 \mathrm{~mm}$ $\mathrm{Hg}(121 \pm 3 \mathrm{~mm} \mathrm{Hg}$ to $134 \pm 4 \mathrm{~mm} \mathrm{Hg}, P<0.025)$. The heart rate increased slightly from $68 \pm 3$ to $76 \pm 4$.

\section{Aortic Regurgitation}

Patients with chronic aortic regurgitation (Table 2) had an ejection fraction of $67.0 \% \pm 4.2 \%$ at rest which was not significantly different from the control population. The ejection fraction after cold changed to only $65.4 \% \pm 3.9 \%$ which was not significantly different from baseline. This lack of an increase in ejection fraction 


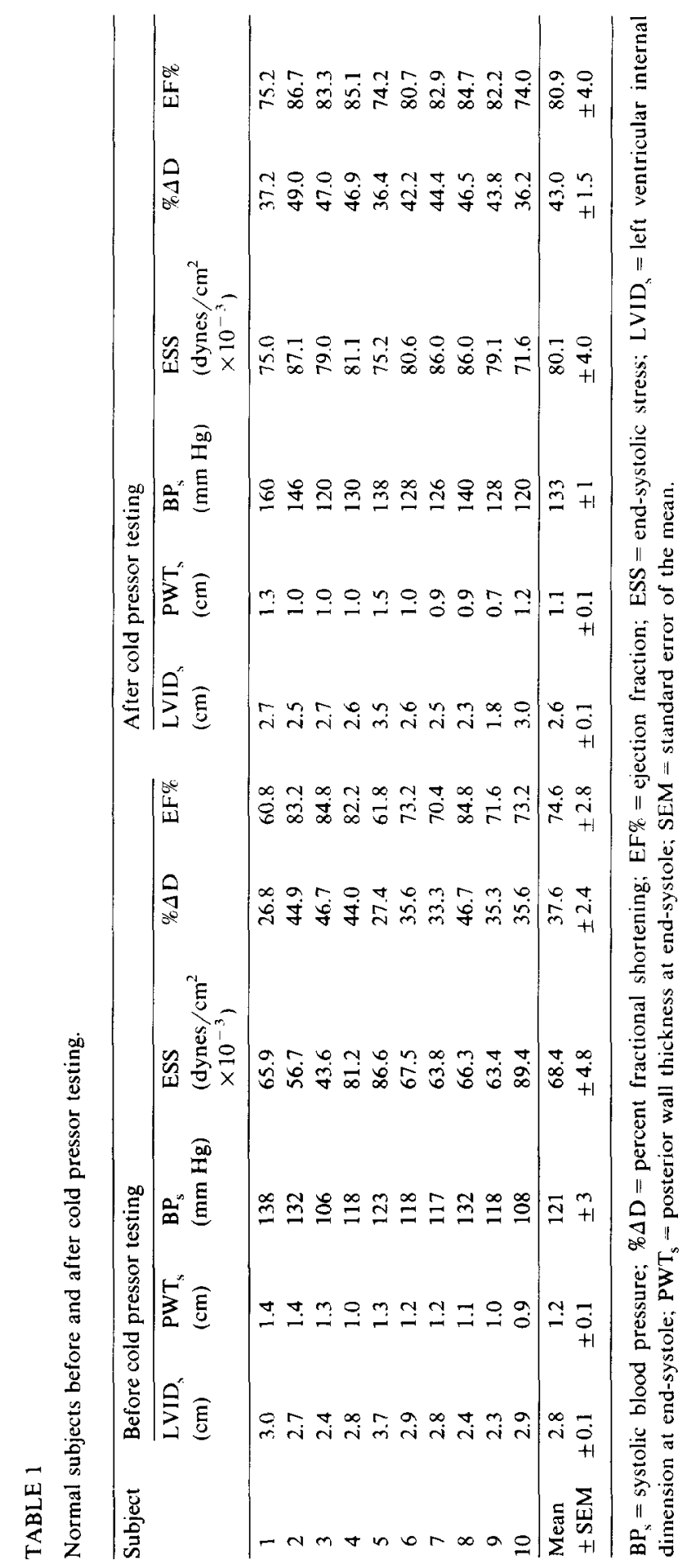




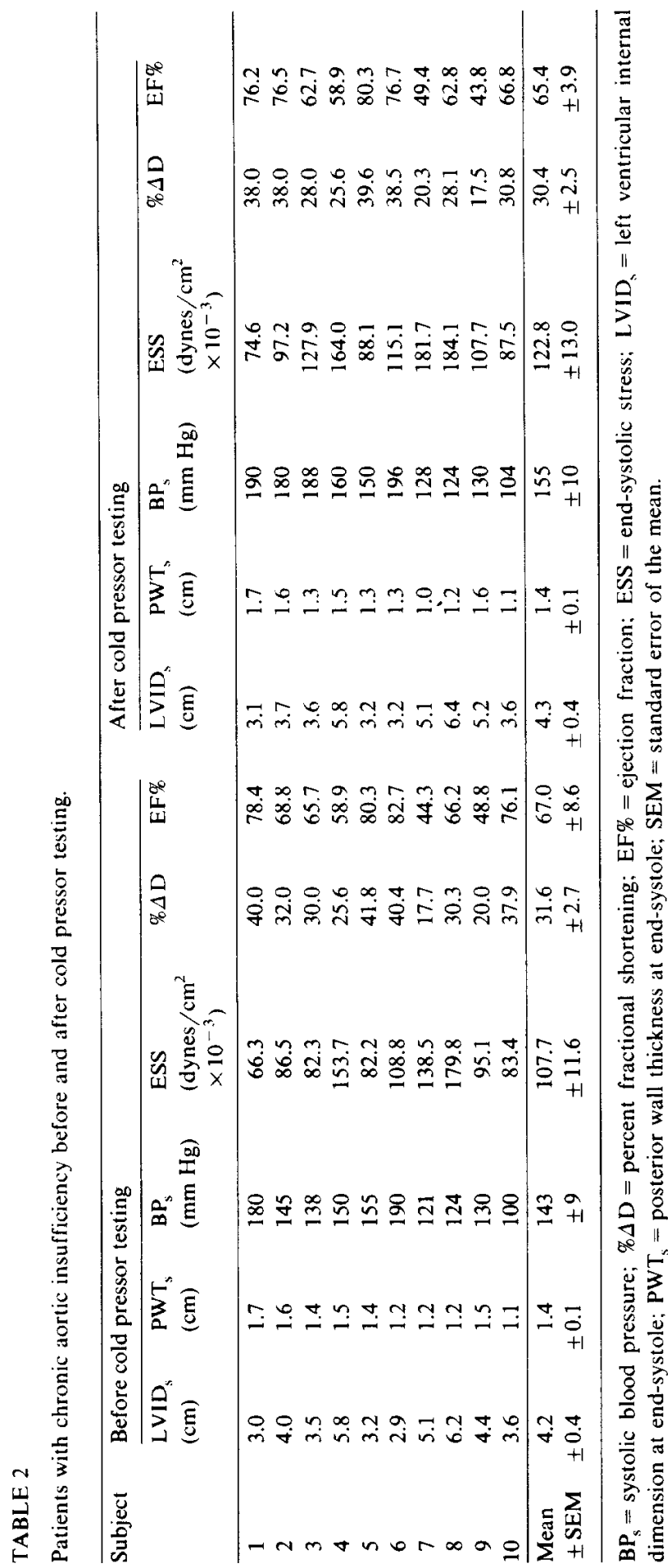


after cold-induced inotropic stimulation and an increase in afterload was markedly different from the increase in ejection fraction noted in the control group $(P<0.005)$. The percent fractional shortening at baseline in the group with aortic regurgitation was $31.6 \% \pm 2.7 \%$ which was also not significantly different from controls. After cold pressor, the percent fractional shortening stayed basically constant at $30.4 \% \pm$ $2.5 \%$ which was highly significantly different from the response of the normal control population $(P<0.0005)$. The end-systolic stress at rest in the patient group was $107.8 \pm 11.6$ dynes $/ \mathrm{cm}^{2} \times 10^{-3}$ which was significantly different from the resting control value $(P<0.005)$. With cold pressor testing, the end-systolic stress rose to $122.8 \pm 13.0$ dynes $/ \mathrm{cm}^{2} \times 10^{-3}$ which was also significantly different from the control group's post-cold pressor value $(P<0.005)$. The only resting difference between the patient group and normal controls was in the end-systolic stress $\left(68.4 \pm 4.8\right.$ dynes $/ \mathrm{cm}^{2} \times 10^{-3}$ vs. $107.7 \pm 11.6$ dynes $\left./ \mathrm{cm}^{2} \times 10^{-3}, P<0.005\right)$ and left ventricular thickness to diameter ratio $(0.43 \pm 0.02$ vs. $0.36 \pm 0.03, P<0.05)$. The average rise in blood pressure was $12 \pm 6 \mathrm{~mm} \mathrm{Hg}(141 \pm 8 \mathrm{~mm} \mathrm{Hg}$ to $151 \pm 10$ $\mathrm{mm} \mathrm{Hg}, P=\mathrm{NS}$ ) which was not different from the response of the normal control group. Heart rate increased slightly from $72 \pm 5$ to $79 \pm 6$. Neither the heart rate in the basal state, or after the cold pressor intervention, nor the degree of increase in the heart rate differed between the two groups.

The end-systolic stress-percent fractional shortening relationship after cold pressor was remarkably different between normal volunteers and patients with aortic regurgitation (Fig. 1). As stress increased in the normal group, the percent fractional shortening increased. Thus, the point defining the relationship moved upward and to the right. There was no change in end-diastolic diameter between the control state or

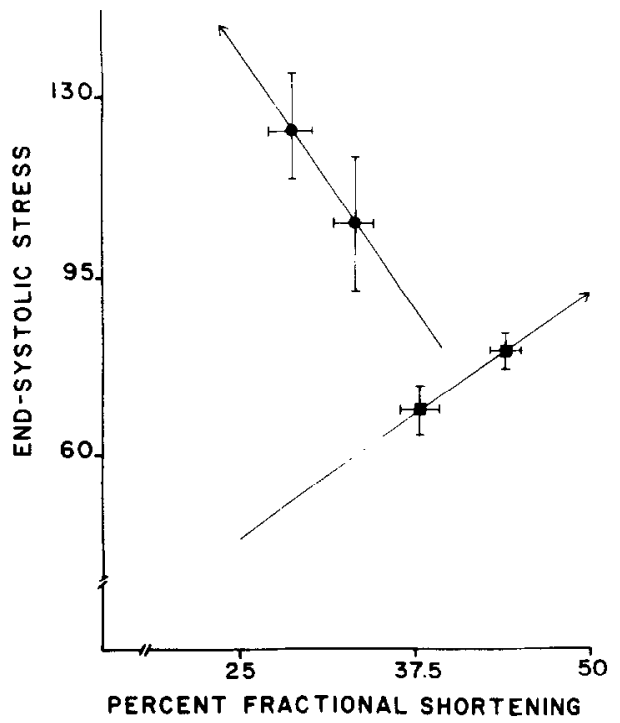

Fig. 1. Relationship between end-systolic stress (dynes $/ \mathrm{cm}^{2} \times 10^{-3}$ ) and percent fractional shortening before and after cold pressor testing in normal subjects $(\boldsymbol{\square})$ and in patients with aortic insufficiency $(\bullet)$. 
after cold pressor. This increase in percent fractional shortening likely represents increased contractility. In 7 patients with aortic regurgitation, the increased stress seen after cold pressor testing was associated with a decrease in percent fractional shortening. and in one patient there was an unchanged percent fractional shortening. Thus, the point defining the relationship moved upward and to the left. In only 2 cases, the percent fractional shortening increased with an increased end-systolic stress. Again, there was no change in end-diastolic diameter.

\section{Discussion}

I eft ventricular function in chronic aortic regurgitation has been difficult to evaluate. Evaluation of ejection phase indices such as resting ejection fraction. regurgitant fraction, and end-diastolic volume have not proved to be predictive of left ventricular function during stress [21-23]. Some studies have suggested that ejection fraction is predictive of left ventricular functional recovery after aortic valve replacement $[24,25]$; whereas others have not $[21,26]$. Ejection fraction may remain normal due to the increased preload seen in states such as aortic regurgitation despite significant left ventricular dysfunction [26], and thus may not reflect changes in left ventricular function during acute alterations in loading conditions [27-29].

\section{End-Systolic Stress}

The degree of left ventricular contraction can be defined by the ventricle's force-length relationship. End-systolic stress represents the load that terminates left ventricular ejection [15]. Thus, end-systolic stress, or force, is directly related to end-systolic volume or length; is load independent, and can be used as a measure of myocardial contractility $[13,14,19]$. In this study, we did not elect to determine left ventricular volumes by M-mode echocardiography due to the inherent inadequacy of that calculation, particularly in large hearts [30-32]. Myocardial contractility, as measured by end-systolic pressure-volume relationships, has been used to evaluate normals [33] and patients with aortic regurgitation $[20,34]$. In those studies, contractile function, as determined by that relationship, only appeared depressed in patients with aortic regurgitation and congestive heart failure. The asymptomatic group was no different compared to the control population; this was also true in our study using this parameter. However, end-systolic pressure does not take into account changes in left ventricular wall thickness which occur in patients with chronic volume overload $[8,35]$.

That end-systolic stress can be accurately estimated from M-mode echocardiographic measurements has been repeatedly validated against angiographically-determined end-systolic stress $[19,20,36]$. Wilson et al. [20] simultaneously performed echocardiograms and high-fidelity left ventricular pressure recordings in patients with aortic regurgitation. They found an excellent correlation between measured end-systolic stress and calculated end-systolic stress $(r=0.99, P<0.001)$, and between end-systolic pressure and peak pressure $(r=0.98, P<0.01)$. They also showed that systolic blood pressure obtained by the cuff method correlated well with 
peak systolic aortic pressure $(r=0.95, P<0.01)$ [20]. Furthermore, it has been suggested that the echocardiographically determined values may be more accurate than the angiographic because the injected contrast material may significantly affect the invasively obtained values [36].

\section{Stress-Shortening Relationship}

Borow et al. [37] studied alterations of stress-fractional shortening relationships in normals using echocardiography. Afterload was altered by the infusion of methoxamine and contractility was altered by the infusion of dobutamine. Linear inverse relationships were defined between stress and shortening. There was no strong correlation between stress and dimension in the control state, however, positive inotropic stimulation always shifted each individual's stress-dimension curve to the right. This suggested that smaller dimensions for any given stress indicated an increase in contractility. Positive inotropic intervention resulted in a higher percent fractional shortening for any end-systolic stress and the change was more discriminating than that of the end-systolic stress-dimension relation. In the present study, all but one of the normal group increased their percent fractional shortening as the stress increased. This increase in percent fractional shortening, despite the increased afterload caused by the cold pressor, suggested an increase in myocardial contractility due to the cold pressor test. In our patients with aortic regurgitation, only two showed an increase in percent fractional shortening as end-systolic stress rose. This suggested decreased myocardial contractility, or a decrease in the ability of the left ventricle in these patients to respond to this inotropic stimulus with simultaneously increased afterload. Heart rate changes were equal in both groups so that changes in the force-frequency relationships did not account for changes in contractility [38]. In the present study, there was no difference in the resting state between the two groups when the ejection phase indices of ejection fraction and percent fractional shortening were compared.

\section{Cold Pressor Testing}

Cold pressor testing was used in this study to evaluate a truly noninvasive method of altering contractility and afterload. Cold immersion causes an acute increase in both systemic blood pressure and heart rate. The average increase in blood pressure in this study was consistent with that found previously [16,39]. This pressor effect is most likely due to an increase in peripheral vascular resistance mediated by the sympathetic nervous system $[17,39,40]$. Cold pressor testing is also believed to cause an increase in myocardial contractility that is not related to changes in diastolic volume [16]. Studies in normals showed an increase in ejection fraction as measured by radionuclide ventriculography after cold pressor testing without an increase in end-diastolic volume. Patients with ischemic heart disease, or cardiomyopathy, had no increase in ejection fraction despite an increase in end-diastolic volume. It has been suggested that the lack of an increase in ejection fraction after cold immersion represents the inability of abnormal myocardium to increase its contractility during 
an increase in afterload [16]. In the present study, 8 of the 10 patients with aortic regurgitation failed to increase their percent fractional shortening after cold pressor testing. This was in marked contradistinction with the ability of nine of the ten normals to increase their percent fractional shortening in the presence of increased end-systolic stress.

The markedly increased end-systolic stress seen in this study, both at rest and after cold pressor in patients with chronic aortic regurgitation, is likely due to inadequate hypertrophy of the left ventricle. This increase in end-systolic stress has been suggested to be predictive of a poor prognosis after aortic valve replacement $[41,42]$. The importance of "adequate" hypertrophy, and therefore normalized end-systolic stress for any given percent fractional shortening, has been implicated indirectly in several studies which found that patients with a high end-diastolic radius-to-wall-thickness ratio did poorly after aortic valve replacement, and did not show significant improvement in left ventricular function, or a decrease in left ventricular internal dimensions [29,43.44]. This index has been suggested to be insensitive, although specific, in identifying patients with a poor prognosis $[5,45]$. Gaasch et al. [46] have recently used systolic pressure times the ratio of left ventricular radius to wall thickness to predict which patients would have a postoperative return towards normal in their left ventricular dimensions and mass. This is very similar conceptually to using the end-systolic stress. The relationship between increased end-systolic stress and poor left ventricular function has also been suggested in hypertensive patients [35]. An inverse relationship between end-systolic stress and left ventricular performance was noted. These investigators also suggested that "inadequate" hypertrophy accounted for the increased stress, and therefore decreased ventricular function [35].

The present study suggests some degree of left ventricular dysfunction in most patients with chronic aortic regurgitation. This is in agreement with experimental data in dogs [47]. All foxhound puppies which had aortic regurgitation produced at four months had increased end-diastolic diameters, a decreased rate of left ventricular contraction and expansion after 2 and 6 months. Our results also agree with those recently reported by Branzi et al. [48]. In their study, they examined end-systolic pressure-volume relationships using M-mode echocardiography during angiotensin infusion in 16 asymptomatic or mildly symptomatic patients with chronic severe aortic regurgitation. They found that the end-systolic pressure-volume relationship was abnormal in $75 \%$ of their patients whereas other traditional ejection phase indices were often normal.

The end-systolic stress-percent fractional shortening relationship, as determined by M-mode echocardiography, can noninvasively detect early myocardial dysfunction in most patients with chronic aortic regurgitation. The value of this parameter in detecting early left ventricular dysfunction in patients with chronic aortic regurgitation, and the prognostic implications of the index, need to be examined in a prospective long-term study. Present decisions on the need for valve replacement are still largely based upon symptoms and the load-dependent indices of left ventricular function, such as changes in ejection fraction during exercise and/or left ventricular end-diastolic diameter. However, these have not correlated well to outcome after 
valve replacement. Only by further prospective, long-term study before and after valve replacement will the full value of the end-systolic stress-dimensional relationships be known.

\section{Acknowledgement}

The authors gratefully acknowledge the assistance of Mrs. Sharon Haglund in the preparation of this manuscript.

\section{References}

1 Samuels DA, Curfman GD, Friedlich AL, Buckely MJ, Austen WG. Valve replacement for aortic regurgitation: long-term follow-up with factors influencing the results. Circulation 1979:60:647-654

2 Spagnulo M, Kloth H, Taranta A, Doyle E, Pasternack B. Natural history of rheumatic aortic regurgitation: criteria predictive of death, congestive heart failure, and angina in young patients. Circulation 1971;44:368-380.

3 Hirshfeld JW Jr, Epstein SE, Roberts AJ, Glancy DL. Morrow AG. Indices predicting long-term survival after valve replacement in patients with aortic regurgitation and patients with aortic stenosis Circulation 1974;50:1190-1199.

4 Braun LO, Kincaid OW, McGoon DC. Prognosis of aortic valve replacement in relation to the preoperative heart size. J Thorac Cardiovasc Surg 1973;65:381-385.

5 Cunha CL, Giuliani ER, Fuster V, Seward JB, Brandenberg KO, MCGoon LC. Preoperative M-mode echocardiography as a predictor of surgical results in chronic aortic insufficiency. $J$ Thorac Cardiovasc Surg 1980;79:256-265.

6 Henry WL, Bonow RO, Borer JS, et al. Observation on the optimum time for operative intervention for aortic regurgitation. Circulation 1980:61:471-483.

7 Forman R, Firth BG. Barnard MS. Prognostic significance of preoperative left ventricular ejection fraction and valve lesion in patients with aortic valve replacement. Am J Cardiol 1980;45:1120 1125.

8 Greves J, Rahimtoola SH, McAnulty JH, et al. Preoperative criteria predictive of late survival following valve replacement for severe aortic regurgitation. Am Heart J 1981;101:300-308.

9 O'Toole JD, Geiser EA, Reddy PS, Curtiss EI, Landfair RM. Effect of preoperative ejection fraction on survival and hemodynamic improvement following aortic valve replacement. Circulation 1978;58:1175-1184.

10 Schuler G, Peterson KL, Johnson AD, et al. Serial noninvasive assessment of left ventricular hypertrophy and function after surgical correction of aortic regurgitation. Am $J$ Cardiol 1979:44:585-594.

11 Borer JS, Bacharach SL. Green MV, et al. Exercise-induced left ventricular dysfunction in symptomatic and asymptomatic patients with aortic regurgitation: assessment with radionuclide cinearlgiography. Am J Cardiol 1978;42:351-357.

12 McDonald IG, Jelinek VM. Serial M-mode echocardiography in severe chronic aortic regurgitation. Circulation 1980;62:1291-1296.

13 Suga H, Sagawa K, Kostiuk D. Load independence of the instant pressure-volume ratio of the canine left ventricle and effects of epinephrine and heart rate on the ratio. Circ Res 1972;32:314-322.

14 Suga $H$, Sagawa K. Instant pressure-volume relationship and their ratio in the excised, supported left ventricle. Circ Res 1974;35:117-126.

15 Sagawa K, Suga H, Shoukas AA, Bakalar KM. End-systolic pressure-volume ratio: a new index of ventricular contractility. Am J Cardiol 1977;40:748-753.

16 Wainwright RJ, Cueni TA, Brennard-Roper DA, Sowton E, Hilson AJ, Maisey MN. Cold pressor test in detection of coronary heart-disease and cardiomyopathy using technetium- $99 \mathrm{~m}$ gated blood-pool imaging. Lancet 1979;2:320-323.

17 Greene MA. Boltax AJ, Lustig GA. Rogow E. Circulatory dynamics during the cold pressor test. Am J Cardiol 1965;16:54-60. 
18 Pombo JF, Troy BL. Russell RO Jr. Left ventricular volumes and ejection fraction by echocardiography. Circulation 1971;43:480-490.

19 Grossman W, Jones D, McLaurin LP. Wall stress and patterns of hypertrophy in the human left ventricle. J Clin Invest 1975:56:56-64.

20 Wilson JR, Rcichek N, Hirshfeld J, et al. Noninvasive assessment of load reduction in patients with asymptomatic aortic regurgitation. Am J Med 1980;68:664-674.

21 Borow KM, Green LH, Mann T, et al. End-systolic volume as a predictor of postoperative left ventricular performance in volume overload from valvular regurgitation. Am J Med 1980;69:655-663.

22 Bolen JL, Holloway EL, Zener JC, Harrison DC, Alderman EL. Evaluation of left ventricular function in patients with aortic regurgitation using afterload stress. Circulation 1976;53:132-138.

23 Cohn PF, Gorlin R, Cohn LH. Collins JJ Jr. Left ventricular ejection fraction as a prognostic guide in surgical treatment of coronary and valvular heart disease. Am J Cardiol 1974;34:136-141.

24 Fischl SJ, Gorlin R. Herman MV. Cardiac shape and function in aortic valve discase: physiologic and clinical implications. Am J Cardiol 1977;39:170-176.

25 Kennedy JW, Twiss RD, Blackmon JR. Dodge HT. Quantitative angiocardiography III. Relationships of left ventricular pressure, volume and mass in aortic valve disease. Circulation 1968;38:838-845.

26 Eckberg DL, Gault JH, Bouchard RL, Karliner J, Ross J Jr. Mechanics of left ventricular contraction in chronic severe mitral regurgitation. Circulation 1973;47:1252-1259.

27 Ross J Jr, Peterson K. On the assessment of the cardiac inotropic state. Circulation 1973:47:435-438.

28 Sonnenblick EH, Strobeck JE. Derived indexes of ventricular and myocardial function. N Engl J Med 1977;296:978-982.

29 Weber KT, Janicki JS, Hefner LL. Left ventricular force-length relations of isovolumic and ejecting contractions. Am J Physiol 1976;231:337-343.

30 Ludbrook P, Karliner JS, Peterson K, Leopold G, O'Rourke RA. Comparison of ultrasound and cineangiographic measurements of left ventricular performance in patients with and without wall motion abnormalities. Br Heart J 1973;35:1026-1032.

31 Fortuin NJ, Hood WP Jr, Sherman ME, Graige E. Determination of left ventricular volumes by ultrasound. Circulation 1971:44:575-584.

32 Salcedo EE. Gockowski K, Tarazi RC. Left ventricular mass and wall thickness in hypertension. Am J Cardiol 1979;44:936-940.

33 Grossman W, Braunwald E, Mann T, McLaurin L, Green L. Contractile state of the left ventricle in man as evaluated from end-systolic pressure-volume relations. Circulation 1977:56:845-852.

34 Osbakken M, Bove AA, Spann JF. Left ventricular function in chronic aortic regurgitation with reference to end-systolic pressure, volume and stress relations. Am J Cardiol 1981:47:193-198.

33 Devereux RB, Savage DD, Sachs I, Laragh JH. Relation of hemodynamic load to left ventricular hypertrophy and performance in hypertension. Am J Cardiol 1983;51:171-176.

36 Brodie BR, McLaurin LP. Grossman W. Combined hemodynamic-ultrasonic method for studying left ventricular wall stress: comparison with angiography. Am J Cardiol 1976;37:864-870.

37 Borow KM, Green LH, Grossman W, Braunwald E. Left ventricular end-systolic stress-shortening and stress-length relations in humans. Am J Cardiol 1982;50:1301-1308.

38 Covell JW. Ross J Jr. Taylor R, Sonnenblick EH, Braunwald E. The effects of increasing frequency of contraction on the force velocity relation of the left ventricle. Cardiovasc Res 1967;1:2-8.

39 Mudge GH Jr, Grossman W, Mills RM Jr. Lesch M. Braunwald E. Reflex increase in coronary vascular resistance in patients with ischemic heart disease. N Engl J Med 1976:295:1333-1337.

40 Gooden JO, Roth GM, Hines EA Jr. The changes in the intra-arterial pressure during immersion of the hand in ice-cold water. Circulation 1955;12:963-973.

41 Kumpuris AG, Quinones MA, Waggoner AD, Kanon DJ, Nelson JA, Miller RR. Importance of preoperative hypertrophy, wall stress and end-systolic diameter as echocardiographic predictors of normalization of left ventricular dilatation after valve replacement in chronic aortic insufficiency. Am J Cardiol 1982;49:1091-1100.

42 Hood WP, Rackley CE, Rolett EL. Wall stress in the normal and hypertrophied left ventricle. Am J Cardiol 1968:22:550-558

43 Gaasch WH. Left ventricular radius to wall thickness ratio. Am J Cardiol 1979;43:1189-1194.

44 Gaasch WH, Andrias CW. Levine HJ. Chronic aortic regurgitation: the effect of aortic valve replacement on left ventricular volume, mass and function. Circulation 1978;58:825-836. 
45 Bonow RO, Rosing DR, Kent KM, Epstein SE. Timing of operation for chronic aortic regurgitation. Am J Cardiol 1982;50:325-336.

46 Gaasch WH, Carroll JD, Levine HJ, Criscitiello MG. Chronic aortic regurgitation: prognostic value of left ventricular end-systolic dimension and end-diastolic radius/thickness ratio. J Am Coll Cardiol 1983;1:775-782.

47 Goldman RA, Christie LG, Geiser EA, et al. Evolution of left ventricular response to chronic aortic insufficiency: results in experimental animals. (abstract) Circulation 1981;64:1V-211.

48 Branzi A, Lolli C, Piovaccari G, et al. Echocardiographic evaluation of the response to afterload stress test in young asymptomatic patients with chronic severe aortic regurgitation: Sensitivity of the left ventricular end-systolic pressure-volume relationship. Circulation 1984;70:561-569. 